\title{
ANALYSIS OF BREECH PRESENTATION
}

\author{
Bhupesh H. Gaikwad', Rahul P. Maskar²
}

${ }_{1}^{1}$ Associate Professor, Department of Obstetrics and Gynaecology, R. C. S. M. Government Medical College, Kolhapur. ${ }_{2}^{2}$ Assistant Professor, Department of Obstetrics and Gynaecology, R. C. S. M. Government Medical College, Kolhapur.

\section{ABSTRACT}

The Breech presentation and its outcome is repeatedly in the past and further consideration will be given in future because of its association with high fetal mortality. The study conducted at present is undertaken to evaluate the fetal outcome by various modes of delivery and factors influencing perinatal mortality and morbidity.

\section{KEYWORDS}

Abnormalities, Imaging, Male, Ultrasonography, Urethra, Urethral Stricture.

HOW TO CITE THIS ARTICLE: Gaikwad BH, Maskar RP. Analysis of breech presentation. J Evolution Med Dent Sci 2016;5(5):

280-282, DOI: $10.14260 /$ jemds/2016/60

\section{INTRODUCTION}

Breech presentation is a commonest form of malpresentation. Breech presentation has been a fascinating, but an equally formidable problem to the obstetricians. The serious factor that an obstetrician faces is the high perinatal morbidity and mortality, whatever may be the mode of delivery. Thus is a challenging problem to the obstetricians for many reasons.

The problem in management of breech presentation are more than those associated with the uncertainties and mechanism of the after coming head. In spite of various methods of diagnosis, antennal care, newer and safe anesthetics and techniques of delivery, breech presentation appears to be a challenge to the obstetric skill and judgment due to the inherent risks presents in such delivery. If breech persists in the later weeks of gestation ECV is tried, but the value of it is controversial.

There is no other subject is obstetrics as controversial as the subject regarding the management of breech presentation. While some believe that caesarean section is the best mode of delivery, others argue vaginal delivery can be as safe as abdominal route if properly conducted. Although rarely stated in print, routine elective cesarean delivery of the breech fetus of any gestational age has been recommended as a means to reduce perinatal morbidity and mortality.1,2 Thus in recent years to avoid trauma for the after-coming head, routine episiotomy, applications of forceps to the after-coming head, liberal use of cesarean section have been recommended.

The study conducted at present is undertaken to evaluate the fetal out come by various modes of delivery and factors influencing perinatal mortality and morbidity. This study was conducted in Government Medical College (RCSM GMC) and the study group included 100 patients with breech presentation prospective study involving the booked and unbooked cases. These patients were studied with respect to their gestational age, birth, weight, type of breech, route of delivery and their effect on the perinatal outcome.

Financial or Other, Competing Interest: None.

Submission 28-11-2015, Peer Review 30-11-2015,

Acceptance 12-01-2016, Published 16-01-2016.

Corresponding Author:

Bhupesh H. Gaikwad,

Flat No. 704,

HR4 Building, Punya Parva

Near Apple Hospital,

Karandemale.

E-mail: bhupeshgaikwad@rediffmail.com

DOI:10.14260/jemds/2016/60

\section{Inclusion Criteria}

- Patients who were 28 weeks and above.

- Birth weight $>1000$ grams.

- Any parity.

\section{Exclusion Criteria}

- Gestational age $<28$ weeks.

- Birth weight $<1000$ grams.

- Transverse lie where the presentation was turned to breech by external manipulation.

- Any case with presentation other than breech where attempts were made to deliver by internal podalic version were excluded.

- Twins.

The incidence in this study was calculated the total number of admission to the corresponding group and also for the total number of breech deliveries.

Complication were in the form of PET, eclampsia, placenta previa, rheumatic heart disease, anemia of the patients and the babies were followed up till the time of discharge, most of the patients were discharged by the second or the third day.

\section{OBSERVATIONS AND RESULTS}

\begin{tabular}{|c|c|c|}
\hline $\begin{array}{c}\text { Total } \\
\text { No. of Deliveries }\end{array}$ & Breech & Percentage \% \\
\hline 2129 & 100 & 4.69 \\
\hline
\end{tabular}

\begin{tabular}{|c|c|}
\hline Age (Yrs.) & Total \% \\
\hline$<=20$ & 30 \\
\hline $21-25$ & 54 \\
\hline $26-30$ & 13 \\
\hline $31-35$ & 2 \\
\hline $36-40$ & 1 \\
\hline
\end{tabular}

Most of the patients were between 21 to 30 years of age.

\begin{tabular}{|c|c|}
\hline Status & Total\% \\
\hline Unbooked & 57 \\
\hline Booked & 21 \\
\hline Referred & 22 \\
\hline
\end{tabular}

Thus majority of the cases were unbooked cases having undergone no antenatal care. 
This had an impact on the fetal outcome. The fetal mortality and morbidity was high among the referred and unbooked patients. Patients mainly came from primary health centers, rural hospitals and sub-district hospitals.

\begin{tabular}{|c|c|}
\hline Type of Breech & Total\% \\
\hline Extended & 60 \\
\hline Complete & 10 \\
\hline Footling & 30 \\
\hline
\end{tabular}

It was observed that incidence of frank breech was more in study group. The exact cause is unknown. The possible explanation is that in primi, the tight abdominal musculature reduces the effective space available for the fetal accommodation and the attitude of universal flexion.

Complications were in the form of PIH, PET, eclampsia, anemia, placenta previa, Rh-ve pregnancy, hydramnios, oligohydramnios. Of the above complications, PIH and anemia constituted the major group. Incidence of PIH was higher in primi gravida. Among the study group two patients have albuminuria, one has to be induced preterm for severe PET; there were fundoscopic changes in the patients.

Hydramnios, the overall incidence in the study was 15\%; $3 \%$ of the patients among this group was associated with some obstetric or fetal complication.

\begin{tabular}{|c|c|c|c|}
\hline Case Admitted & No. of Cases & PNM & \% \\
\hline Booked & 21 & 2 & 9.52 \\
\hline Unbooked & 57 & 20 & 35.08 \\
\hline Referred & 22 & 2 & 9.09 \\
\hline
\end{tabular}

In the study group there were FSB (8), MSB (6), NND (10) Incidence was more in emergency group in many cases, no decision could be made. Maternal morbidity was mainly related to the associated conditions inherent to pregnancy, especially in multi's.

Most of the studies in this series was based on the fetal outcome with regard to gestational age, birth weight and mode of delivery. The incidence obtained in this study was compared to different studies as quoted in the journals and books.

\begin{tabular}{|c|c|}
\hline Authors & Incidence (\%) \\
\hline Present study & 4.69 \\
\hline Manju Mishtra. ${ }^{3} 1973$ & 2.44 \\
\hline Hall et al.4 965 & 3.17 \\
\hline R. Sivaraman. ${ }^{5}$ & 2.71 \\
\hline JJ. Rovinsky. ${ }^{6}$ & 4.1 \\
\hline Kamala Jayaram. ${ }^{7} 1986$ & 2.8 \\
\hline Kamala Kidhar. ${ }^{8} 1993$ & 3.36 \\
\hline Dunn et al. $1962 .{ }^{9}$ & 3.3 \\
\hline T.D. Tank.10 1993 & 3.6 \\
\hline Waidenbach A. ${ }^{11}$ & 3.6 \\
\hline Pratima Hegde Patil.12 & 3.27 \\
\hline
\end{tabular}

The incidence of breech presentation in this series was comparable to other authors as shown in the table. The incidence in present series $(4.69 \%)$ was found to be slightly high as compared to other studies. This is because of large number of referred cases and also because ECV was not practiced as the criteria were not met with.

Western authors have reported higher incidence of breech presentation in primi's, but in India the incidence is more in multi's than in primi probably due to greater number of multigravidae and their association with complications like twins, increased incidence of congenital anomalies which predispose to breech presentation.

In the present study incidence of extended breech presentation was $60 \%$, complete breech $10 \%$ and footing breech $30 \%$. The incidence of extended breech was more.

\begin{tabular}{|c|c|c|c|}
\hline Authors & Extended & Complete & Footing \\
\hline Present Study & $60 \%$ & $10 \%$ & $30 \%$ \\
\hline Kamala Jayararam. $^{7}$ & $84 \%$ & $9.5 \%$ & $6.5 \%$ \\
\hline Kohiya \& Masani. $^{13}$ & $25.7 \%$ & $54.6 \%$ & $21.87 \%$ \\
\hline Williams \& Graves. $^{14}$ & $52.65 \%$ & $7.5 \%$ & $42.3 \%$ \\
\hline Pratima Hegade. $^{12}$ & $96.3 \%$ & $1.1 \%$ & $3.2 \%$ \\
\hline R. Sivaraman. $^{6}$ & $42.39 \%$ & $23.64 \%$ & $11.77 \%$ \\
\hline
\end{tabular}

The significance of complications in the study group was that these conditions predisposed to breech presentation and also to preterm labour which itself was the cause of breech presentation. Labour had to be induced in two cases of severe PET who subsequently developed eclampsia. Major groups of complications in this study group were anemia, toxemia and hydramnios. In the present study the incidence of complicated breech was $56 \%$.

According to hall and Raul (1936) prematurity is an single most important cause of high perinatal mortality rate. Kamala Jayaranr. ${ }^{7}$ gives an incidence of $14.4 \%$ for fetal deaths due to prematurity in the present series perinatal mortality rate was high largely because of many number of unbooked and complicated referral cases. According to Kamala Jayaram. ${ }^{7}$ perinatal mortality for the vaginal group (24\%) was more compared to caesarean section (1\%). The present study also correlates well with the above author where it was $21 \%$ for vaginal group and 3.03 for caesarean section group.

In the present study the major indication for caesarian section was fetopelvic disproportion and fetal distress in primi, whereas it was previous lower segment caesarean section in multigravida. A study by Malhotra. ${ }^{15}$ 1993, concludes that although combined intrapartum and neonatal mortality was significantly higher for vaginal delivery.

In the present study, there is one case of $\mathrm{BOH}$ who had suffered 3 abortions (Cause not known) went into preterm labour and the decision was made to deliver per abdomen. In the present study the incidence was $7 \%$.

In the present study, 21 cases delivered vaginally suffered mild birth asphyxia and has to be shifted to NICU. Such babies were treated with oxygen under high pressure and kept under warm environment. In the present study there was no maternal mortality. Morbidity after vaginal breech delivery was similar to vaginal vertex delivery.

\section{DISCUSSION}

1. Incidence of breech in the present study is $4.69 \%$.

2. Incidence was more in multigravida. The commonest presentation is frank breech.

4. In the present study most of the babies weight between 2-3 kilograms.

5. Age incidence was common between $21-25$ years in the study group.

6. In the present study commonest mode of delivery was assisted breech delivery $45 \%$.

7. Caesarean section rate was $48 \%$ more in primi. 
8. Caesarean section rate was comparatively higher in primi gravida patients.

9. In the study group, emergency and referred admission were more compared to booked cases.

10. Incidence of complicated cases was $56 \%$. The commonest complications in the group was toxemia, anemia, hydramnios and prematurity.

11. Fetal complications were in the form of cord prolapse $4 \%$, PROM, fetal distress $12 \%$.

12. Incidence of congenital anomaly was $7 \%$.

13. Uterine malformations were in the form of actuate of and septate uterus, incidence was $3 \%$.

14. Gross perinatal mortality in the study group was $24 \%$.

15. Commonest indications for caesarean section in primi was fetopelvic disproportion and fetal distress and in multi was previous caesarean section.

16. Average duration of labour for primi was $14-16$ hours and multi was 8-10 hours.

17. Commonest cause of perinatal death was prematurity and birth asphyxia.

18. Perinatal mortality was more in relation to footling breech.

19. Perinatal mortality was more in multipara.

20. Perinatal morbidity was more in patients with history of PRO.

21. There was no maternal mortality in the study group and no severe morbidity.

\section{ABBREVATIONS}

- + Present

- $\quad$ - Not present

- 1 HR $1^{\text {st }}$ stage of labour in hours

- 2 HR $2^{\text {nd }}$ stage of labour in hours

- $\quad 3$ MIN $3^{\text {TM }}$ stage of labour in minutes

- A and $\mathrm{H}$, Alive and healthy

- ANAE, Anaemia

- APH, Antepartum haemorrhage

- $\mathrm{AU}$, Arcuate uterus

- B, Booked

- $\mathrm{BE}$, Breech extraction

- DIL, Dilatation

- Eff, Effacement

- IUD Intrauterine death

- $\mathrm{CP}$, Cord prolapse

- FD, Fetal distress

- L Footling

- LSCS, Lower segment cesarean section

- FHS, Fetal heart sound

- FSB, Fresh still birth

- C, Complete

- G, Gravida

- $\mathrm{GH}, \mathrm{Gross}$ hydrocephalus

- HyD, Hydramnios

- IUGR, Intrauterine growth retardation

- MAC, Macerated

- ME, Membrane

- MRP, Manual removal of placenta

- $\mathrm{MSB}$, Macerated still birth

- NND, Neonatal death

- O-OP, Obstetric operation

- PLSCS, Previous lower segment cesarean section
- PD, Post dated

- PP, Placenta praevia

- $\quad$ PROM, Premature rupture of membrane

- $\quad \mathrm{R}$, Referred

- RHD, Rheumatic heart disease

- $\mathrm{RP}$, Retained placenta

- $\quad \mathrm{SB}$, Still birth

- SPON, Spontaneous

- STA, Station

- TOX, Toxemia

\section{BIBLIOGRAPHY}

1. Wright RC. Reduction of perinatal mortality and morbidity in the breech delivery through routine use of caesarean section. Obstet Gynecol 1959;14:758.

2. Bingham P, Lilfort RJ. Management of the selected term breech presentation; assessment of the risks of selected vaginal delivery versus cesarean section for all cases. Obstet Gynecol 1987;69:965.

3. Mishra M, Singh D. Place of caesarean section with reference to improving foetal salvage in breech presentation. J of Obstet and Gynecol of India 1979;29: 4-9.

4. Hall JE, Kahl S. Breech presentation. AM J Obstet Gynecol 1956;72:977-990.

5. Woods J. Effect of low birth weight and breech delivery in neonatal mortality. Obstet Gynecol 1979;53:735.

6. Joseph J, Rovinsky J, Miller A, et al. Managament of breech presentation at term. Am J Obstet Gynecol 1973;115:497.

7. Kamala JV, Parameswari T. Analysis of 518 cases of breech deliveries during a 5 year period. J of Obstet and Gynecol of India 1995;45:431.

8. Sidkar K, Gupta BN, Sandu K. Comparative study of perinatal mortality in different malpresentation. J of Obstet and Gynecol of India 1995;30:4-5.

9. Leo J Dunn, Voorhis LV, Napier J. Term breech presentation. Obstet Gynecol 1965;25:322.

10. Tank, Devis ES, Holt R. Mechanisms of trauma during breech delivery. Obstet Gynaecol 1971;38:761.

11. Weidenbach A, Klse BJ, Langer F, et al. Term breech delivery-evolution and management. 1976;36:820-827.

12. Hegde-Patil PS, Walwekar V. Factors affecting relationship of breech delivery to perinatal outcome. J of Obstet and Gynecol of India 1999;49:41-46.

13. Kohiyar GA, Masai KM. A critical review of 1110 breech deliveries at Nowrosjee Wadia Maternity Hospital. J of Obstet and Gynecol of India 1964;14:197.

14. Wiliams Graves. Mode of delivery in breech presentation. Am J of Obstet Gynecol 1980;137:229.

15. Malhotra D, Gopalan S, Narang A. Preterm breech delivery in a developing country. Int J Gynaecol Obstet 1994;45:27-34. 